\title{
A CACNA1A variant associated with trigeminal neuralgia alters the gating of Cav2.1 channels
}

\author{
Eder Gambeta, Maria A. Gandini, Ivana A. Souza, Laurent Ferron and Gerald W. Zamponi* (i)
}

\begin{abstract}
A novel missense mutation in the CACNA1A gene that encodes the pore forming $a_{1}$ subunit of the Cav2.1 voltagegated calcium channel was identified in a patient with trigeminal neuralgia. This mutation leads to a substitution of proline 2455 by histidine $(\mathrm{P} 2455 \mathrm{H})$ in the distal C-terminus region of the channel. Due to the well characterized role of this channel in neurotransmitter release, our aim was to characterize the biophysical properties of the P2455H variant in heterologously expressed Cav2.1 channels. Whole-cell patch clamp recordings of wild type and mutant Cav2.1 channels expressed in tsA-201 cells reveal that the mutation mediates a depolarizing shift in the voltage-dependence of activation and inactivation. Moreover, the $\mathrm{P} 2455 \mathrm{H}$ mutant strongly reduced calcium-dependent inactivation of the channel that is consistent with an overall gain of function. Hence, the P2455H Cav2.1 missense mutation alters the gating properties of the channel, suggesting that associated changes in Cav2.1-dependent synaptic communication in the trigeminal system may contribute to the development of trigeminal neuralgia.
\end{abstract}

Keywords: P/Q channel, Calcium channel, Facial pain, lon channel, Electrophysiology

\section{Introduction}

Trigeminal neuralgia (TN) is one of the most common forms of craniofacial pain. TN is defined as sudden unilateral severe short-lasting pain in one or more branches of the trigeminal nerve [1]. The etiology of TN can be classified into (1) classical TN, which is related to neurovascular compression in the root entry zone at the trigeminal ganglia, (2) secondary TN which is associated with neurological diseases such as multiple sclerosis, and (3) idiopathic TN with unknown etiology [2]. With an incidence of 4-13 cases per 100,000 people, it has been reported that $\mathrm{TN}$ can exhibit familial linkage [3], suggesting that some forms of TN may have a genetic component that could be polygenic and multifactorial.

*Correspondence: zamponi@ucalgary.ca

Department of Physiology and Pharmacology, Alberta Children's Hospital Research Institute, Hotchkiss Brain Institute, Cumming School

of Medicine, University of Calgary, Calgary, Canada
A recent study reported that patients with familial TN exhibit rare variants in ion channels, including the $\mathrm{Ca}_{\mathrm{v}} 2.1$ voltage gated calcium channel [4]. $\mathrm{Ca}_{\mathrm{V}} 2.1$ encodes native P-and Q-type calcium channels [5]. These channels are expressed at high levels in trigeminal neurons, the trigeminal sensory nuclear complex, the brain stem, cerebral cortex and cerebellum, where their main function is to control the release of neurotransmitters $[6,7]$. The pore forming $\mathrm{Ca}_{\mathrm{v}} 2.1 \alpha_{1}$ subunit encompasses four major transmembrane domains, each containing six transmembrane segments termed S1-S6. The S4 segment senses membrane potential changes, whereas the linker between S5 and S6 lines the pore of the channel. Cytoplasmic regions connecting the various domains are involved in channel regulation, as are the $\mathrm{N}$ - and $\mathrm{C}$-termini (Fig. 1a). The latter is a key site for calcium regulation of $\mathrm{Ca}_{\mathrm{V}} 2.1$ channel activity [8]. The $\mathrm{Ca}_{\mathrm{V}} 2.1 \alpha 1$ subunit associates with ancillary $\alpha_{2} \delta$ and $\beta$ subunits to form a functional original author(s) and the source, provide a link to the Creative Commons licence, and indicate if changes were made. The images or other third party material in this article are included in the article's Creative Commons licence, unless indicated otherwise in a credit line to the material. If material is not included in the article's Creative Commons licence and your intended use is not permitted by statutory regulation or exceeds the permitted use, you will need to obtain permission directly from the copyright holder. To view a copy of this licence, visit http://creativecommons.org/licenses/by/4.0/. The Creative Commons Public Domain Dedication waiver (http://creativeco mmons.org/publicdomain/zero/1.0/) applies to the data made available in this article, unless otherwise stated in a credit line to the data. 
channel [7]. Multiple splice isoforms of $\mathrm{Ca}_{\mathrm{V}} 2.1$ have been reported in the literature [9].

Mutations in the CACNA1A gene (which encodes $\mathrm{Ca}_{\mathrm{V}}$ 2.1) have been identified in patients with other forms of craniofacial pain, including familial hemiplegic migraine type 1 (FHM-1) [1, 6, 10]. A new missense mutation $(\mathrm{P} 2455 \mathrm{H})$ identified by Di Stefano and colleagues appears to be the first $\mathrm{Ca}_{\mathrm{V}} 2.1$ calcium channel mutation to be associated with a patient with classical TN [4]. Here we use functional expression in heterologous systems along with electrophysiological measurements to demonstrate that this variant causes a gain-of-function of channel activity.

\section{Materials and methods Molecular cloning}

The wild-type human $\mathrm{Ca}_{\mathrm{V}} 2.1$ $\alpha 1$ subunit (+47 exon; NM_023035.1) clone in pcDNA3.1 Zeo (+) was kindly provided by Dr. Terrance Snutch (University of British Columbia, Vancouver, BC, Canada). Site-directed mutagenesis was performed using PCR (Pfu polymerase) along with forward and reverse mutagenesis primers for insertion of the $\mathrm{P} 2455 \mathrm{H}$ mutation. After mutagenesis, the construct was analyzed by DNA sequencing.

\section{Cell culture and transfection}

Human embryonic kidney tsA-201 cells were cultured and transiently transfected using the calcium phosphate method. Cells were transfected with $3 \mu \mathrm{g}$ of $\mathrm{hCa}_{\mathrm{V}} 2.1 \alpha_{1}+47$ or $\mathrm{P} 2455 \mathrm{H}+47$ in combination with the auxiliary subunits $\beta_{4}$ and $\alpha_{2} \delta-1$, and $0.5 \mu \mathrm{g}$ of eGFP to identify transfected cells.

\section{Electrophysiology recordings}

Whole-cell voltage-clamp recordings were performed at room temperature $\left(22-24{ }^{\circ} \mathrm{C}\right) 72 \mathrm{~h}$ post transfection. Currents were recorded using an Axopatch 200B amplifier linked to a computer with pCLAMP9.2 software. The external solution contained (in $\mathrm{mM}$ ): $2 \mathrm{CaCl}_{2}$ or $5 \mathrm{BaCl}_{2}, 137$ or $132.5 \mathrm{CsCl}, 1 \mathrm{MgCl}_{2}, 10 \mathrm{HEPES}$ and 10 glucose (pH 7.4 adjusted with $\mathrm{CsOH}$ ). Patch pipettes were filled with an internal solution containing (in
$\mathrm{mM}): 130 \mathrm{CsCl}, 2.5 \mathrm{MgCl}_{2}$, 5 EGTA, 10 HEPES, $3 \mathrm{Na}$ ATP and 0.5 Mg-GTP (pH 7.4 adjusted with $\mathrm{CsOH}$ ).

Peak current was determined by applying $250 \mathrm{~ms}$ pulses between $-60 \mathrm{mV}$ and $+30 \mathrm{mV}$ in $5 \mathrm{mV}$ increments from a holding potential of $-100 \mathrm{mV}$ to obtain the current-voltage $(I-\mathrm{V})$ relation. The current densityvoltage relationship was obtained by dividing the peak current at each voltage by the cell capacitance. The $I-V$ curves were fitted using the following Boltzmann equation: $\quad\left(\mathrm{I}=\left(\left(V_{\mathrm{mem}}-V_{\text {rev }}\right) \times G_{\mathrm{max}}\right) /\left(1+\exp \left(\left(V_{\mathrm{mem}}-V_{\mathrm{h}, \text { act }}\right) /\right.\right.\right.$ $\mathrm{d} x)$ ). Where $I$ is the peak current, $V_{\text {mem }}$ is the membrane potential, $V_{\text {rev }}$ is the reversal potential, $G_{\max }$ is the maximum conductance, $V_{\mathrm{h} \text {, act }}$ is the half voltage for activation, and $\mathrm{d} x$ is the slope factor. Time constants of activation $\left(\tau_{\text {act }}\right)$ were obtained by mono-exponential fits to the late rising phase of the current using the following equation: $I=A \times(1-\exp (-t / \tau))$, where $A$ is the amplitude of the current, and $\tau$ is the time constant. Activation curves were obtained from the $I-V$ curves by dividing the peak current at each depolarizing step by the driving force according to the equation: $G=I /\left(V_{\text {mem }}-V_{\text {rev }}\right)$ and normalized against the maximum conductance $\left(G_{\max }\right)$.

Steady-state inactivation curves were obtained by applying $5 \mathrm{~s}$ conditioning pre-pulses from $-80 \mathrm{mV}$ to $+30 \mathrm{mV}$ in $5 \mathrm{mV}$ increments followed by a $140 \mathrm{~ms}$ test pulse to $-5 \mathrm{mV}$. Curves were fitted with the equation: $I / I_{\max }=1 /\left(1+\exp \left(-\left(V_{\text {mem }}-\mathrm{V}_{\mathrm{h} \text {, inact }}\right) / \mathrm{d} x\right)\right)$ where $V_{\mathrm{h}}$, inact is the half inactivation potential. Inactivation kinetics were determined by measuring the current remaining at the end of a $240 \mathrm{~ms}$ depolarization. Recovery from inactivation was evaluated by applying two test pulses, P1 (2s) and P2 (5 ms), at $0 \mathrm{mV}$ that were separated by an interval ranging from $20 \mathrm{~ms}$ to $7.5 \mathrm{~s}$ with a holding potential of $-100 \mathrm{mV}$. P2/P1 was plotted as a function of time.

\section{Data analysis}

Data were analyzed using Clampfit 10.3 software (Molecular Devices) and fitted using GraphPad Prism 8. All averaged data are plotted as mean \pm SEM. Statistical analysis was performed using a two-tailed Student's $t$ test and $\mathrm{p}<0.05$ was considered significant.

\footnotetext{
(See figure on next page.)

Fig. 1 Functional effects of the $\mathrm{P} 2455 \mathrm{H}$ mutation on channel activation. a Schematic representation of the $\mathrm{Ca}_{\mathrm{V}} 2.1 \mathrm{a}_{1}$ subunit with the approximate location of the Proline 2455 Histidine (P2455H) mutation in the C-terminus. b Representative calcium current traces recorded from Cav2.1 $a_{1}+47 /$ $\beta_{4} / a_{2} \delta-1$ and $\mathrm{P} 2455 \mathrm{H}+47 / \beta_{4} / a_{2} \delta-1$ channels. c Average current density-voltage relationship for cells expressing $C_{2} 2.1 a_{1}+47 / \beta_{4} / a_{2} \delta-1$ or $\mathrm{P} 2455 \mathrm{H}+47 / \beta_{4} / \mathrm{a}_{2} \delta-1$ channels. $\mathbf{d}$ Normalized activation curves. Inset: mean voltage for half activation for $\mathrm{Ca}_{\mathrm{v}} 2.1 \mathrm{a}_{1}+47 / \beta_{4} / \mathrm{a}_{2} \delta-1$ or P $2455 \mathrm{H}+47 /$ $\beta_{4} / a_{2} \delta-1$ channels ( ${ }^{* *} p=0.0077$, two-tailed Student's t test). e Average peak current density for whole cell calcium currents recorded from cells expressing Cav $2.1 a_{1}+47 / \beta_{4} / a_{2} \delta-1$ or P2455H $+47 / \beta_{4} / a_{2} \delta-1$ channels ( $p=0.8914$, two-tailed Student's t test). f Time constant of current activation $\left(\tau_{\text {act }}\right)$ as a function of voltage $\left({ }^{*} \mathrm{p}<0.05 ;{ }^{* *} \mathrm{p}<0.01 \mathrm{vs} C \mathrm{a}_{\mathrm{v}} 2.1 \mathrm{a}_{1}+47 / \beta_{4} / \mathrm{a}_{2} \delta-1\right.$, two-tailed Student's $t$ test). Data are represented as mean \pm SEM. Numbers in parentheses represent the number of cell recordings per variant
} 


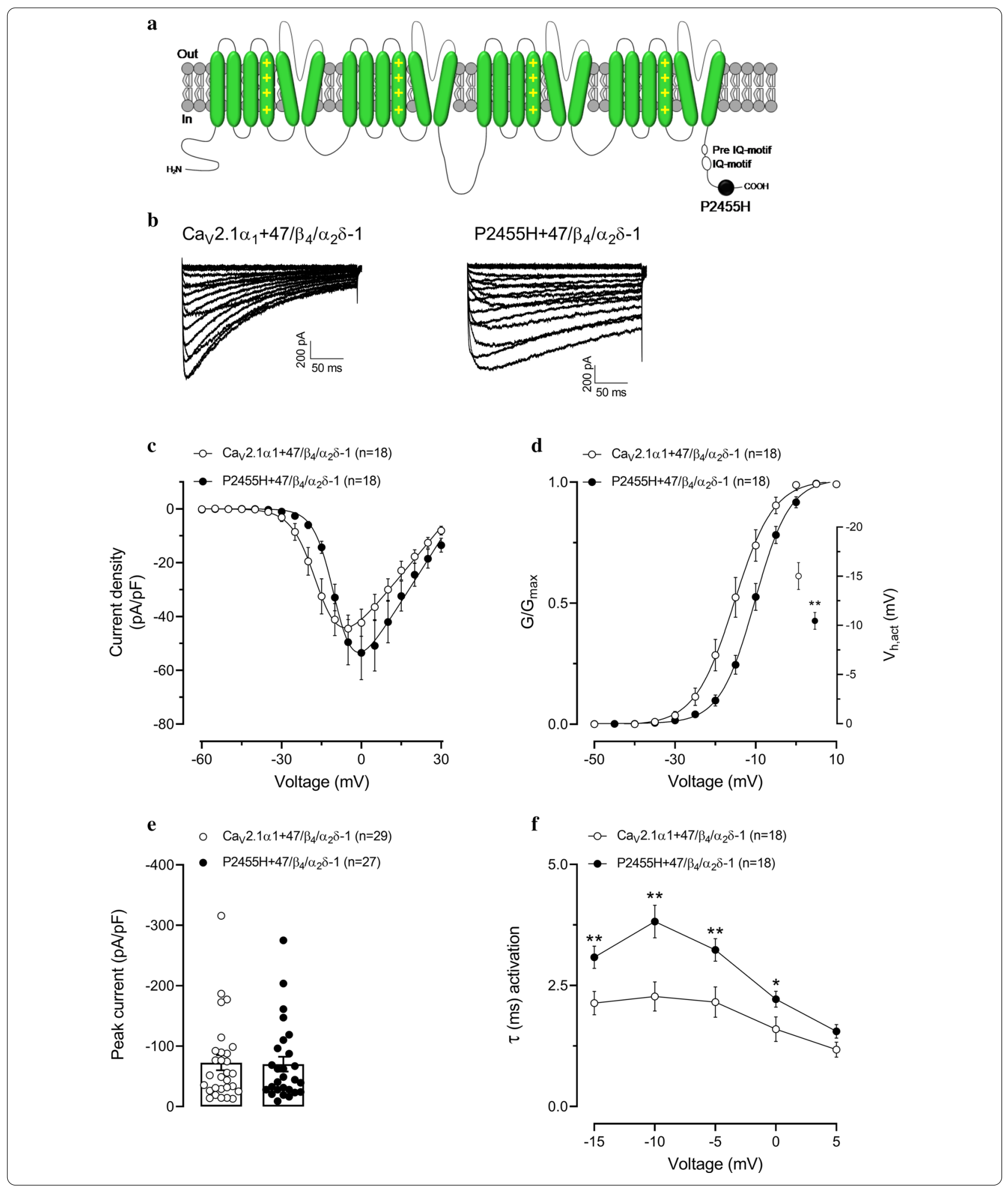

\section{Results and discussion}

We characterized the influence of the $\mathrm{P} 2455 \mathrm{H}$ mutation (Fig. 1a) on $\mathrm{Ca}_{\mathrm{V}} 2.1$ channel activity in a bath solution containing $\mathrm{Ca}^{2+}$ as the carrier ion. Representative traces for each variant are shown in Fig. $1 b$ and reveal an apparent slowing of inactivation kinetics in the mutant 

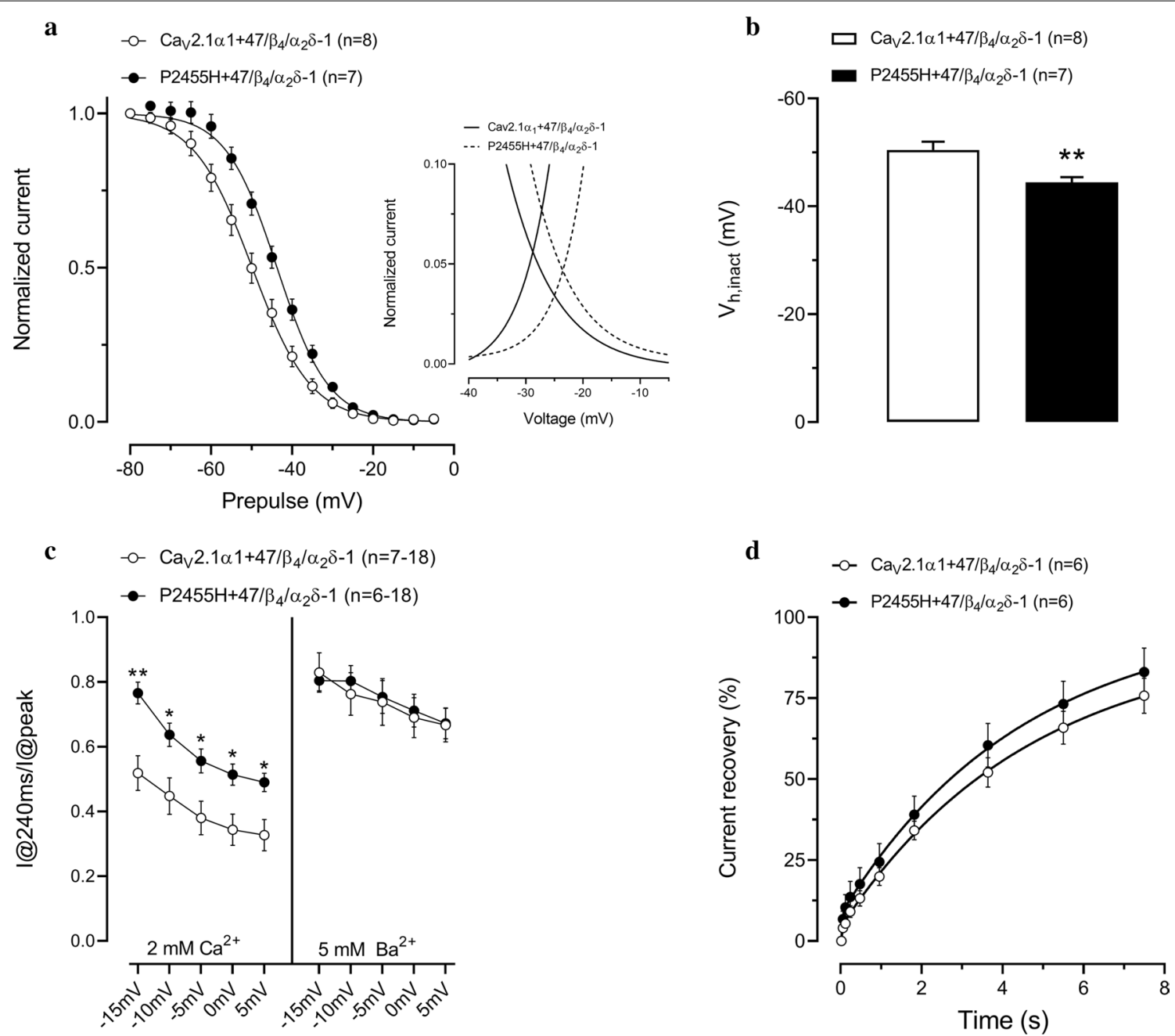

Fig. 2 Functional effect of the P2455H mutation on Cav2.1 inactivation. a Steady-state inactivation curves for $C a_{v} 2.1 a_{1}+47 / \beta_{4} / a_{2} \delta-1$ or $\mathrm{P} 2455 \mathrm{H}+47 / \beta_{4} / \mathrm{a}_{2} \delta-1$ channels. Inset: overlap of the activation and inactivation curves to illustrate the size and position of the window current. $\mathbf{b}$ Mean voltage for half inactivation for $C a_{V} 2.1 a_{1}+47 / \beta_{4} / a_{2} \delta-1$ or $P 2455 H+47 / \beta_{4} / a_{2} \delta-1$ channels $\left({ }^{* *} p=0.0073\right.$, vs Ca $2.1 a_{1}+47 / \beta_{4} / a_{2} \delta-1$, two-tailed Student's t test). c Fraction of current remaining at the end of a 240 ms depolarizing pulse using $\mathrm{Ca}^{2+}$ or $\mathrm{Ba}^{2+}$ as a charge carrier $\left({ }^{*} p<0.05\right.$ and ${ }^{* *} p=0.0076$, two-tailed Student's t test). $\mathbf{d}$ Comparison of the time course of recovery from inactivation for $\mathrm{Ca}_{\mathrm{v}} 2.1 \mathrm{a}_{1}+47 / \beta_{4} / \mathrm{a}_{2} \delta-1$ and $\mathrm{P} 2455 \mathrm{H}+47 / \beta_{4} / \mathrm{a}_{2} \delta-1$ channels. Data are represented as mean \pm SEM. Numbers in parentheses represent the number of cells recordings per variant

channel. Figure 1c shows the current density-voltage relations for wild type and mutant $\mathrm{Ca}_{\mathrm{V}} 2.1$, revealing that the mutant exhibited a depolarizing shift in the voltagedependence of activation $\left(\mathrm{Ca}_{\mathrm{V}} 2.1 \mathrm{:}-15.02 \pm 1.36 \mathrm{mV}\right.$; P2455H: $-10.45 \pm 0.88, p=0.0077$, see also Fig. 1d). Furthermore, no difference was observed on peak current between both groups (Fig. 1e), and no change in cell surface expression of $\mathrm{P} 2455 \mathrm{H}$ was observed when assayed via cell surface biotinylation (data not shown). The P2455H mutation mediated a slowing of the time course for activation (Fig. 1f).

Inspection of steady-state inactivation curves reveals that the mutant channel exhibits a depolarizing shift in the half inactivation potential (Fig. 2a, b), indicating a greater availability for opening $\left(\mathrm{Ca}_{\mathrm{V}} 2.1\right.$ : $-50.44 \pm 1.53 \mathrm{mV} ; \quad \mathrm{P} 2455 \mathrm{H}: \quad-44.45 \pm 0.98 \mathrm{mV}$, $\mathrm{p}=0.0073$ ). As a consequence of the effects of the mutation on the voltage-dependences of activation and inactivation, the peak of the window current is shifted to more depolarizing potentials (Fig. 2a inset). We also assessed inactivation kinetics of the channel at multiple test potentials by measuring the fraction of current remaining at the end of a $240 \mathrm{~ms}$ depolarization. Figure 2c (left) shows that the $\mathrm{P} 2455 \mathrm{H}$ exhibits slowed inactivation kinetics across the studied voltage range. To distinguish whether this effect was due to alterations in 
$\mathrm{Ca}^{2+}$ - or voltage-dependent inactivation, we performed a set of recordings with $\mathrm{Ba}^{2+}$ as a charge carrier (Fig. 2c, right). When $\mathrm{Ca}^{2+}$ was removed, the difference in the inactivation kinetics between the wild type and mutant channel was abolished, indicating that the mutation affects $\mathrm{Ca}^{2+}$-dependent inactivation, rather than voltagedependent inactivation kinetics. There was no difference in the time course of recovery from inactivation (Fig. 2d).

Collectively, our findings indicate that the $\mathrm{P} 2455 \mathrm{H}$ mutation identified in a patient with TN [4] mediates compromised voltage-dependent activation, compromised $\mathrm{Ca}^{2+}$-dependent inactivation, and compromised steady-state inactivation of $\mathrm{Ca}_{V} 2.1$. It is interesting to note that pathogenicity algorithms do not predict a pathogenic role of this variant, and yet, there are clear changes in the gating properties. This shows the importance of conducting functional analyses. Mutations in the C-terminal region of $\mathrm{Ca}_{\mathrm{V}} 2.1$ channel have already been described in other pathologies including FHM-1, episodic ataxia type II and spinocerebellar ataxia type 6 [10]. Of particular note, many of the characterized FHM-1 mutations lead to a gain-of-function in channel activity [6], in some cases in a channel splice isoform dependent manner [11]. Here we report that the TN mutation $\mathrm{P} 2455 \mathrm{H}$ also causes a gain-of-function by inhibiting inactivation, but at the same time a loss of function due to reduced activation gating. How these alterations in biophysical changes manifest themselves physiologically may depend on different subtypes of neurons that are present in trigeminal ganglia [12]. For example, gain-ofchannel function due to slowing of inactivation may have a more profound impact in neurons with high frequency firing, whereas the depolarizing shift in activation and the associated reduction of function may be more important in neurons with lower firing rates. Along these lines, it is known that gain-of-function mutations in $\mathrm{Ca}_{\mathrm{v}} 2.1$ channels have been associated with conditions such as FMH-1 [13] due to a hyperpolarizing shift in the half activation voltage of the channel that enhances excitatory synaptic transmission and leads to cortical spreading depression. The gain-of-function observed here affects predominantly the inactivation properties of the channel, thus perhaps accounting for the absence of FHM-1 in this patient. We also note that the pathology in the affected patient became evident after age 46 [4]. In this context, we note that the patient's MRI also showed a neurovascular compression [4], and it is thus possible that the effect of the mutation only manifested itself after this additional physical injury.

It is interesting to note that amino acid substitution drastically reduced $\mathrm{Ca}^{2+}$-dependent inactivation, even though the mutated residue lies downstream of the pre-IQ and IQ motifs that are known to interact with calmodulin and are critical for this type of inactivation (Fig. 1a) [14, 15]. These data thus reveal a previously unrecognized role of the distal $\mathrm{Ca}_{\mathrm{V}} 2.1 \mathrm{C}$-terminus region in calcium regulation of $\mathrm{Ca}_{\mathrm{v}} 2.1$. The molecular basis of this effect remains to be determined, although it is worth noting that the distal C-terminus in $\mathrm{Ca}_{\mathrm{V}} 1.4$ channels has been shown to mediate an auto-inhibition of $\mathrm{Ca}^{2+}$-dependent inactivation [14, 16]. $\mathrm{Ca}_{\mathrm{V}} 2.1$ plays a critical role in neurotransmitter release, and hence, a gain-of-function of channel activity is consistent with enhance synaptic transmission in the trigeminal system $[14,15]$. Furthermore, the C-terminal region of $\mathrm{Ca}_{\mathrm{v}} 2$ channels is known to be involved in the tethering of synaptic vesicles [17] and it is thus possible that the mutation may interfere with this process. Collectively, this may explain the increase in the affected individual's nociceptive processing.

In summary, to our knowledge, the $\mathrm{P} 2455 \mathrm{H}$ variant was the first $\mathrm{Ca}_{\mathrm{V}} 2.1$ channel mutation to be associated with trigeminal neuralgia. Our data demonstrate that this new missense variant in the CACNA1A gene mediates both gain and loss of function effects in Cav2.1 that are expected to affect signal processing in the trigeminal system.

\section{Abbreviations \\ TN: Trigeminal neuralgia; FMH-1: Familial hemiplegic migraine type 1.}

\section{Acknowledgements}

We thank Lina Chen for preparation of cell cultures.

\section{Authors' contributions}

EG conceived the study and wrote the manuscript. EG, MAG, IAS, and LF performed experiments and analyzed data. GWZ supervised the study and edited the manuscript. All authors read and approved the final manuscript.

\section{Funding}

E.G. is funded by a studentship from the Cumming School of Medicine and Alberta Innovates (AI). M.A.G. holds postdoctoral fellowships from Canadian Institute of Health Research (CIHR). G.W.Z. holds a Canada Research Chair and holds a CIHR Foundation grant.

Availability of data and materials

All data generated or analyzed during this study are included in this published article.

Ethics approval and consent to participate

Not applicable.

Consent for publication

Not applicable.

Competing interests

The authors declare no competing interest.

Received: 25 November 2020 Accepted: 28 December 2020 Published online: 07 January 2021

\section{References}

1. Headache Classification Committee of the International Headache Society (IHS). The International Classification of Headache Disorders, 3rd edition. Cephalalgia. 2018;38(1):1-211. 
2. Gambeta E, Chichorro JG, Zamponi GW. Trigeminal neuralgia: an overview from pathophysiology to pharmacological treatments. Mol Pain. 2020;16:1744806920901890.

3. Jones MR, Urits I, Ehrhardt KP, Cefalu JN, Kendrick JB, Park DJ, et al. A comprehensive review of trigeminal neuralgia. Curr Pain Headache Rep. 2019;23(10):74.

4. Di Stefano G, Yuan JH, Cruccu G, Waxman SG, Dib-Hajj SD, Truini A. Familial trigeminal neuralgia - a systematic clinical study with a genomic screen of the neuronal electrogenisome. Cephalalgia. 2020:40(8):767-77.

5. Mori Y, Friedrich T, Kim MS, Mikami A, Nakai J, Ruth P, et al. Primary structure and functional expression from complementary DNA of a brain calcium channel. Nature. 1991;350(6317):398-402.

6. Pietrobon D, Striessnig J. Neurobiology of migraine. Nat Rev Neurosci. 2003;4(5):386-98.

7. Zamponi GW, Striessnig J, Koschak A, Dolphin AC. The physiology, pathology, and pharmacology of voltage-gated calcium channels and their future therapeutic potential. Pharmacol Rev. 2015;67(4):821-70.

8. Ben-Johny M, Dick IE, Sang L, Limpitikul WB, Kang PW, Niu J, et al. Towards a unified theory of calmodulin regulation (calmodulation) of voltage-gated calcium and sodium channels. Curr Mol Pharmacol. 2015;8(2):188-205.

9. Soong TW, DeMaria CD, Alvania RS, Zweifel LS, Liang MC, Mittman S, et al. Systematic identification of splice variants in human P/Q-type channel alpha1(2.1) subunits: implications for current density and $\mathrm{Ca}^{2+}$-dependent inactivation. J Neurosci. 2002;22(23):10142-52.
10. Pietrobon D. CaV2.1 channelopathies. Pflugers Arch. 2010;460(2):375-93.

11. Adams PJ, Garcia E, David LS, Mulatz KJ, Spacey SD, Snutch TP. Ca(V)2.1 P/Q-type calcium channel alternative splicing affects the functional impact of familial hemiplegic migraine mutations: implications for calcium channelopathies. Channels (Austin). 2009;3(2):110-21.

12. Telka MV, Rikhalsky OV, Veselovsky NS. Excitability properties of trigeminal ganglion neurons. Fiziol Zh. 2016;62(2):24-34.

13. van den Maagdenberg AM, Pietrobon D, Pizzorusso T, Kaja S, Broos LA, Cesetti T, et al. A Cacna1a knockin migraine mouse model with increased susceptibility to cortical spreading depression. Neuron. 2004;41(5):701-10

14. Budde T, Meuth S, Pape HC. Calcium-dependent inactivation of neuronal calcium channels. Nat Rev Neurosci. 2002;3(11):873-83.

15. Catterall WA, Few AP. Calcium channel regulation and presynaptic plasticity. Neuron. 2008;59(6):882-901.

16. Striessnig J, Pinggera A, Kaur G, Bock G, Tuluc P. L-type $\mathrm{Ca}(2+)$ channels in heart and brain. Wiley Interdiscip Rev Membr Transp Signal. 2014;3(2):15-38.

17. Wong FK, Nath AR, Chen RH, Gardezi SR, Li Q, Stanley EF. Synaptic vesicle tethering and the CaV2.2 distal C-terminal. Front Cell Neurosci. 2014;8:71.

\section{Publisher's Note}

Springer Nature remains neutral with regard to jurisdictional claims in published maps and institutional affiliations.
Ready to submit your research? Choose BMC and benefit from:

- fast, convenient online submission

- thorough peer review by experienced researchers in your field

- rapid publication on acceptance

- support for research data, including large and complex data types

- gold Open Access which fosters wider collaboration and increased citations

- maximum visibility for your research: over $100 \mathrm{M}$ website views per year

At $\mathrm{BMC}$, research is always in progress.

Learn more biomedcentral.com/submissions 